Fecha de recepción: abril 2019

Fecha de aceptación: octubre 2019

Versión final: diciembre 2019

\section{Libertadores; bicentenarios de las independencias en el cine ${ }^{1}$}

Claudia Bossay P. *

Resumen: Durante los bicentenarios de las independencias en Latinoamérica se gestó una amplia producción audiovisual creada por y para la televisión y el cine, la cual reflexionaba sobre las independencias y las colonias. Entre esta vasta producción se destaca la colección Libertadores, que estaba diseñada para estar compuesta por ocho cintas de ficción histórica que narrarían épicas historias de líderes independentistas de distintos países latinoamericanos: Argentina, Brasil, Chile, Cuba, México, Perú, Uruguay y Venezuela. En su primera etapa, esta colección fue co-producidas por la productora española Wanda Films, junto con Lusa Films y la empresa de radio y televisión pública española, TVE junto a productoras locales de Latinoamérica tanto privadas como estatales, de cine y televisión. El proyecto enfrentó dificultades en su concretización, y sufrió un hiato en la mitad del proceso de producción. Para ser luego retomada en parte, estrenando una obra recién el 2017, y cancelando la última obra. La colección Libertadores se puede caracterizar como 'cine de cruces': nacionales e internacionales, de distintos medios y con distintos modos de creación y reflexión visual, respondiendo a todas estas distintas idiosincrasias. Analizando siete obras, el presente capítulo evalúa qué elementos de los pasados fundacionales de las repúblicas latinoamericanas se decidieron destacar durante las celebraciones de los bicentenarios de las independencias, reflexionando en torno al presente de los periodos de producción. Se destacan particularmente la radiografía de modos y estados de producción de las obras en Latinoamérica; la representación de las dinámicas entre el imperio español y los revolucionarios y victoriosos latinoamericanistas; las manifestaciones de autodeterminación que aparecen en las obras, y finalmente, los aspectos de las individualidades de los libertadores. Este estudio busca de este modo, identificar cómo estas historofotias independentistas se convierten en una propuesta valórica para entender la identidad de los pueblos del bicentenario en el mundo globalizado.

Palabras claves: historiofotía - representación - independencia - identidad - coproducción.

[Resúmenes en inglés y portugués en las páginas 116-117]

${ }^{(*)}$ Licenciada en Historia de la Universidad Diego Portales de Chile. Tiene un Magíster en Estudios interdisciplinarios y un Doctorado en Estudios de Cine, ambos de Queen's University Belfast, Irlanda del Norte. Actualmente, continúa su investigación sobre representaciones del pasado en el audiovisual a través de un post doctorado de FONDECYT, que se realiza en el Instituto de la Comunicación e Imagen, de la Universidad de Chile, en donde investiga la colonia y la independencia Latinoamericana. Además, es docente de la 
misma casa de estudios y tiene diversas publicaciones y reseñas en revistas nacionales e internacionales.

\section{Introducción}

Adelantándose a la polémica de este año en el Festival de Cannes sobre el futuro de la exhibición de cine asociado a Netflix y la televisión, el año 2009 en el Festival de cine de San Sebastián, el director del área de cine de la empresa de radio y televisión pública española TVE, Gustavo Ferrada, presentó la colección de películas Libertadores. Esta constaría de ocho cintas de ficción histórica que narrarían épicas historias de líderes independentistas de ocho países latinoamericanos. En esa ocasión, Ferrada dijo que la televisión pública española quería "apoyar las efemérides que permiten contribuir a recuperar nuestra historia común e impulsar vínculos culturales con países con los que mantenemos unas intensas relaciones políticas, diplomáticas, comerciales y sociales”. Además, declaró que con "la producción y emisión de la colección Libertadores, TVE se suma a la celebración de los bicentenarios de las primeras independencias de las repúblicas latinoamericanas"2. Así, esta serie pensada para audiencias globales de cine y televisión busca representar las idiosincrasias latinoamericanas desde nuestra historia para impulsar una identidad que vaya más allá de los marcos nacionales. La serie se realiza con objetivos pragmáticos, como la diplomacia y el comercio, pero también como reflejo del momento histórico contemporáneo de las naciones del bicentenario.

El formato de este gigantesco proyecto de cine ibero-latinoamericano fue impulsado por TVE, junto con Wanda Films, productora presidida por José María Morales, y Lusa Films, compañía productora del actor español Sancho Gracia, quien falleciera en el año 2012. Ambas empresas en su rol de productoras ejecutivas se asocian con productoras, canales de televisión y otras fuentes de financiamiento de cada uno de los países participantes de la serie: Argentina, Brasil, Chile, Cuba, México, Perú, Uruguay y Venezuela. Gracia, de Lusa Films, comentó en el mismo evento en San Sebastián, que el origen del proyecto provenía de su cariño por España, donde nació, y Uruguay, donde se crió tras el exilio de su familia producto de la Guerra Civil española. "Sentí la necesidad de devolver a España y a Latinoamérica algo, y eso se transformó en Libertadores" (Vertele.es, 2009). De este modo, Gracia pone en relevancia cómo las fronteras, los exilios y las identidades globales del pasado y el presente han configurado la región.

En orden de estreno, las obras de esta serie son: José Martí. El ojo del canario (2009, Cuba), dirigida y escrita por Fernando Pérez; Revolución, el cruce de Los Andes (2010, Argentina), también conocida como San Martín, el cruce de Los Andes, dirigida por Leandro Ipiña con guión de Andrés Maino e Ipiña; Hidalgo. La historia jamás contada (2010, México), dirigida por Antonio Serrano con guión de Serrano y Leo Mendoza; La Redota: una historia de Artigas (2011, Uruguay), dirigida por César Charlone con guión de Charlone y Pablo Vierci; Bolivar. El hombre de las dificultades (2013, Venezuela), dirigida por José Luis Lamata con guión de José Luis Varela, José Antonio Varela y Luis Alberto Lamata; O'Higgins. El niño rojo (2014, Chile), dirigida por Ricardo Larraín con guión de Larraín y Andrés 
Kalawski. Recién estrenada el año 2017; y Joaquim (Portugal, Brasil), dirigida y escrita por Marcelo Gomes. Finalmente, el proyecto original contemplaba una obra sobre José Gabriel Condorcanqui Noguera, conocido popularmente como Tupac Amaru, líder peruano de la independencia, sin embargo por las tardanzas asociadas a la producción de esta, se canceló (Morales, 2018).

Como bien sugiere Rosenstone (1995), toda película histórica habla más bien de su propio presente que del pasado representado. Desde el período silente, las cinematografías latinoamericanas sobre la colonia han transformado narrativas europeas de este pasado y versiones del contacto de los indígenas con el colonizador en comentarios sobre la identidad nacional contemporánea a la realización (Gordon, 2009, p. 1). Es más, el académico estadounidense Richard Gordon propone que "si las películas históricas latinoamericanas generalmente marcan un deseo de auto examinación, [...] las obras sobre la colonia, en particular, revelan una ominosa voracidad de apelar al pasado para repensar el presente" (2009, p. 5, traducción propia). Por este motivo, a continuación analizaremos las siete películas de la serie que se realizaron, tomando en cuenta cuatro aspectos principales: el formato de producción de las obras, la representación de las dinámicas entre los imperios y los victoriosos, las manifestaciones de la autodeterminación y los aspectos de las individualidades de los libertadores. Esto tiene por objetivo comprender qué de estos pasados fundacionales de las repúblicas latinoamericanas se decidió destacar durante las celebraciones de los bicentenarios de las independencias.

\section{El proyecto Libertadores: coproducciones intercontinentales}

Para Morales, de Wanda Films, "era importante contar con buenos directores y productores de cada uno de los países y que tuvieran independencia creativa” (Morales, 2018). Destacó además dos peculiaridades de la colección, que podemos reconocer sobre todo para la primera etapa de la colección:

La primera, que se trata de una producción mayoritariamente española que $d a$ $v o z$ a América en el bicentenario de las independencias de la región, y la segunda, el importante apoyo del sector público a esta producción tanto en España como en América Latina (Vertele.es, 2009, énfasis propio).

Quisiera comenzar analizando el segundo aspecto.

La serie Libertadores está compuesta de interesantes productos unitarios creados en base a recursos mixtos. José Martí. El ojo del canario, fue realizada por Work in progress, TVE, el Instituto Cubano de Artes e Industria Cinematográficos (ICAIC), Lusa Films y Wanda Films. De todas las obras, es la más concreta en su producción, con los tres socios españoles, el socio mayoritario local y la productora encargada. Por su parte, Revolución, el cruce de Los Andes fue realizada desde el Instituto Nacional de Cine y Artes Audiovisuales (INCAA) con el apoyo de 200 Años Bicentenario Argentino, el Gobierno de San Juan, el Espacio para la Memoria y para la Promoción y Defensa de los Derechos Humanos y la Universidad Nacional de General San Martín. Los españoles aparecen en los créditos de la obra: 
primero TVE, luego Wanda Films y, por último, Lusa Films. Se agradece en los créditos el apoyo de las autoridades del Estado, como la Presidencia, los gabinetes de ministerios, de la presidencia y el ministro de educación, además del directorio de Radio y Televisión Argentina (RTA), de diversas autoridades de TV Pública y Educ.ar. S. E., y de autoridades del Canal Encuentro. En esta obra, la aparición de los españoles es solo evidente tras ver toda la película y leer los créditos. Estos también evidencian un gran esfuerzo proveniente de fondos públicos argentinos, y apoyos universitarios, ministeriales y de gobernación. Hidalgo. La historia jamás contada, fue realizada por México 2010, institución que veló por las celebraciones del bicentenario mexicano, el Consejo Nacional para la Cultura y las Artes (Conaculta) -actual Secretaría de Cultura-, el Instituto Mexicano de Cinematografía, Grupo Financiero Inbursa y Astillero Films, en coproducción con Wanda Films, Lusa Films, TVE y Estudios Churubusco Azteca, S.A., dependiente de la Secretaría de Cultura. También contó con el apoyo de BBVA Bancomer y el Gobierno del Estado de Michoacán (2008-2012). Esta película además fue realizada con el estímulo fiscal 226 de la LISR (EFICINE), utilizado por Cryoinfa, José Cuervos y Cinépolis, La Capital del Cine. De este modo, la obra se pudo realizar con el apoyo del Estado, los españoles y empresas privadas que participaron de la obra mediante estímulos fiscales. La Redota: una historia de Artigas es presentada por Antel, la empresa de comunicaciones de los uruguayos, y TVE. Fue producida por TVE, Wanda Films, Lusa Films, Aim Producciones y Cimarrones Películas, en asociación con La Vorágine Films (Uruguay) y Synchro Image (Paraguay). Además, contó con el apoyo de ICAU, "Un cine, un país", Ejército Nacional, Montevideo de Todos, Montevideo Socio Audiovisual, Fondos de Incentivo Cultural, Fuerza Aérea Uruguaya y Banco República. Por ende, recibió una mayor cantidad de apoyo de diversas productoras privadas y estatales que las obras anteriores.

Por su parte, Bolívar. El hombre de las dificultades, se realizó en coproducción con La Villa del Cine, Alter producciones -quienes comúnmente trabajan con canales de televisión inglesa, italiana, española, estadounidense y venezolana, entre otros- y el ICAIC, con el apoyo de la Armada Bolivariana de Venezuela. O'Higgins. El niño rojo es una coproducción con El asombro, Máquina de ideas -de uno de los productores, Luigi Araneda-, BWN Bowen -productora de otro de los productores, Alex Bowen-, Cine XXI y Ricardo Larraín Producciones -del director- con el apoyo de CORFO, Universidad Mayor y el Consejo Nacional de Televisión (CNTV), en conjunto con los españoles. Es decir, contó con fondos estatales y privados, específicamente del mundo universitario.

Finalmente, para el estreno de Joaquim, TVE ya había cerrado su presupuesto del proyecto Libertadores y por lo tanto no colaboró con esta obra, y por lo tanto no tiene colaboración española. En cambio fue una producción Luso-portuguesa de Imovision, Anacine Agência Nacional do Cinema, ICA Instituto do Cinema e do Audiovisual, FSA Fundo Setorial do Audiovisual, BRDE Banco Regional de Desenvolvimento do Extremo Sul, con el incentivo de FUNDARPE Fundação do Patrimônio Histórico e Artístico de Pernambuco, la Secretaría de cultura y el y el Gobierno de Pernambuco, y producido con recursos del Programa Ibermedia, en coproducción con Telecine, con el patrocinio del programa cultural de Petrobras, junto con Rec Productores Asociados (Brasil), en coproducción con Ukbar Filmes (Portugal) y con Wanda Films, Misti Produções, Dezenove Som e Imagens, Estúdios Quanta y Kerkov como productores asociados. Al mismo tiempo fue distribuida 
internacionalmente por Films Boutique, la que la llevó a estrenarse en la competencia del 67 Festival Internacional de Berlín 2017. Pese a que Lusa Films tampoco participó de esta cinta, en los créditos hay una sección de agradecimientos especiales a Sancho Gracia y también a José María Morales quien fue un productor asociado.

En total, hay más de cincuenta socios de producción, asociación y apoyo, donde numéricamente, la mayoría de los socios son de cada uno de los países. También existen colaboraciones entre países latinoamericanos, como el ICAIC. Aunque esto fue más bien la excepción, siendo así obras intercontinentales pero no panamericanas. Así, hay fondos públicos y privados, con el apoyo de leyes de fomento a la cultura y el cine, ayuda de las fuerzas armadas de distintos países, además de empresas privadas e instituciones educacionales. Sin embargo, en términos económicos y cuantitativos, la mayoría de los fondos fueron entregados por los socios españoles. RTVE informa que el 65\% del presupuesto provenía de ellos (Lorite, 2011). Según Alex Bowen, productor ejecutivo de O'Higgins, el niño rojo, la inversión de los españoles correspondió casi a dos tercios del total de la obra (Bowen, 2017).

Al mismo tiempo, son películas para cine -todas las obras fueron filmadas en $35 \mathrm{~mm}$, salvo la chilena, filmada en HDCAM- y para televisión. Pensadas para moverse de una forma de exhibición a la otra, así como para públicos de cada nación, del continente y de España, donde serían exhibidas también en televisión, aunque esto a la fecha aún no sucede. También fueron estrenadas separadamente en reconocidos festivales, donde ganaron varios premios. En sus propios países, se exhibieron tanto en cine como en televisión, incursionando en modos más allá del telefilm e incluso convirtiéndose en series de televisión, como en el caso chileno, o exhibiéndose en plazas y escuelas, como en el caso argentino.

Debido a los elementos internacionales de producción, exhibición y contenidos celebratorios de los bicentenarios, el académico ecuatoriano Noah Zweig ha descrito esta colección como 'crossover cinema' o cine que tiene la "habilidad de transgredir fronteras de géneros, audiencias y cultura, así como también límites entre lo personal/poético y lo político, donde los constantes cruces de fronteras y negociaciones de los realizadores denotan las influencias y afiliaciones interculturales de estos" (2013, p. 38, traducción propia). Estos cruces se manifiestan en las hibridaciones de géneros (histórico, biográfico, épico, aventura, bélico, romántico) y los modos (íntimos, de recreación histórica, reflexivos), así como en la distribución y recepción de las obras pensadas desde lo local hasta lo internacional, en cine y televisión u otros formatos, como DVD, y con exhibiciones en otros espacios no convencionales.

Eso sí, el proyecto Libertadores, tal como las independencias mismas, no ha sido nada de fácil. Se necesitaron magnas coordinaciones intercontinentales, las cuales generaron una primera etapa de éxitos correspondiente a las primeras cuatro películas, que se estrenaron relativamente seguidas y fueron parte de un mismo ímpetu. Luego, tras el fallecimiento de uno de los productores, Sancho Gracia, hubo un pequeño hiato de dos años para luego volver con el proyecto.

Es entonces cuando se estrenan las obras de Venezuela y Chile. El caso de Bolívar. El hombre de las dificultades es bastante interesante, ya que el socio principal, La Villa del Cine, ha sido catalogado por Zweig como uno de los medios en que el estado chavista logra mantener una crítica al neoliberalismo, al mismo tiempo que acomoda esta doctrina al país. Por 
lo tanto, las cintas de esta productora serían sintomáticas del populismo y, de este modo, "las obras de cine hagiográficas que celebran líderes del pasado se convierten en convenientes distracciones para obviar estas contradicciones" (1993, p. 37). Un año después del estreno de esta obra, se lanzó otra más sobre Bolívar: Libertador (Alberto Arvelo, 2014), que contó con un gran presupuesto -(50 millones de dólares) siendo la película más cara realizada en Latinoamérica- y tuvo un reconocido elenco internacional (González, 2013). Ambas películas, sin embargo, fueron criticadas por sus guiones. En el caso de Chile, el proyecto se inició para luego detenerse un par de veces por falta de fondos. Durante una de estas pausas apareció Wanda Films, a través de Bowen, el productor ejecutivo, quien había trabajado previamente con Wanda Vision en una obra de su autoría Mi mejor enemigo (2005, Chile, España, Argentina). En relación a la obra brasilera, estrenada tres años más tarde que la última de la colección, las colaboraciones ya no son las iniciales del proyecto. La muerte de Gracia calza con el fin del gobierno de José Luis Zapatero en España (20042011), el cual se había caracterizado por un gran apoyo a las artes y la cultura. Luego, con el gobierno de Mariano Rajoy (2011-2015 y, actualmente, en gobierno en su segundo período), los fondos para apoyar la cultura decrecieron o sencillamente se cerraron ${ }^{3}$. Según un Dossier sobre la serie, facilitado por Wanda Films, el proyecto fue apoyado por la Secretaría General Iberoamericana, el Secretario de Estado de Cooperación Internacional para Iberoamérica y el Caribe, la Dirección de Relaciones Culturales y Científicas de la AECID, la Comisión Nacional para la Conmemoración de los Bicentenarios de la Independencia de las Repúblicas Iberoamericanas adscrita a la Vicepresidencia Primera del Gobierno de España, el Instituto Cervantes, la Sociedad Estatal para la Acción Cultural Exterior y la Sociedad Estatal de Conmemoraciones Culturales (SECC) (Wanda, 2010). La Secretaría de Estado era dependiente del Ministerio de Asuntos Exteriores y de Cooperación, y desapareció con la reestructuración ministerial de 2017. En 2010, la SECC se convirtió en Acción Cultural Española AC/E. De las otras instituciones, algunas dicen no tener conocimiento de este proyecto. Por ejemplo, el área técnica de cine y audiovisual del Instituto Cervantes dice no haber participado en él. La Dirección de Relaciones Culturales y Científicas de la Agencia Española de Cooperación Internacional para el Desarrollo (AECID) también afirma no haber participado y que, de haberlo hecho, habría sido indirectamente a través del programa Ibermedia. A su vez, Ibermedia dice no haber colaborado (correspondencia personal). En su página, solo aparece Joaquim como parte de las obras que ha apoyado y La Redota, como parte del proyecto El cine de Ibermedia TV. Todo esto ha hecho difícil poder rastrear los dineros y cuantificar los aportes exactos de una u otra parte. Como comentó Morales, la mayoría de los fondos, tanto en las primeras películas como en las posteriores al 2011, vinieron de la inversión española -salvo para el caso de Joaquim, en dónde España no financia sino Portugal y Brasil-y, tanto en los países europeos como en los latinoamericanos, los socios y colaboradores fueron mayoritariamente de instituciones estatales.

Sabemos que la preproducción en varios de los casos fue extensa. Por ejemplo, en el caso de la obra brasilera estuvo siete años en producción de guión. Leandro Ipiña, director de la cinta argentina, comenta que el trabajo de investigación fue de casi cinco años, que comenzó para una serie de televisión y luego se utilizó también para la película. La profundidad alcanzada por la investigación le 
...permitió [...] reconstruir bastante fielmente, en base a documentos, la estética de ese momento, que es una estética que no conocemos, que estaba totalmente....no diría olvidada, pero hay muy poco material visual de ese momento, y generalmente todo lo que hay posterior es una reinterpretación un poco romántica, si es a través de pintura, o un poco marcial, si es a través de la reconstrucción de algunos regimientos históricos... (Pagés, 2011).

Es efectivamente la reconstrucción de la época en detalladas puestas en escena lo que ayuda a crear un imaginario de las independencias. Por su parte, Fernando Pérez, director de la obra cubana, comenta que se realizó una

Investigación muy cuidadosa en la cual colaboraron Gloria María Cosío y Alejandro Gutiérrez. Visitar bibliotecas, consultar periódicos de la época y libros de historia me acercó a la vida en el siglo XIX y pude establecer comparaciones con nuestra vida de hoy (Barceló Vázquez) ${ }^{4}$.

Así, la serie Libertadores es un interesante producto del mundo globalizado, y éste influencia su creación, distribución y exhibición. Como propone Zweig, esta globalización económica y de producción también pone en evidencia los "cruces de fronteras", las influencias y filiaciones intelectuales de los directores y sus equipos de producción.

\section{Los imperios en la colección Libertadores}

Felipe González, ex presidente del Gobierno de España (1982-1996) y Embajador Plenipotenciario de España para las Conmemoraciones de las Independencias de América, realzó que el proyecto "le da voz a los que tenían que tenerla para interpretar su propio devenir histórico" (Lorite, 2011, énfasis propio). Es interesante tomar en cuenta que todos los libertadores representados en esta serie ya habían sido objeto de obras audiovisuales que los representaban 5 , por lo que más que una voz, que ya se tenía, lo que se entregó fue dinero para sumar otras voces a las historiofotías del tema. Es más, los procesos de los bicentenarios locales crearon varias obras audiovisuales adicionales para conmemorar, educar y entretener ${ }^{6}$. Si bien el lenguaje de González es bastante equívoco, pareciera que la serie Libertadores es más bien un intento de los españoles de hacer el gesto de conceder la victoria. De hecho, incluso sugiere en su discurso que "¡Ojalá hiciéramos lo mismo en el norte de África! Darles voz a los protagonistas, [...] y no lecciones de democracia”.

Rafael de España argumenta en su libro Las sombras del desencuentro que el cine español ha tendido históricamente a la no representación de las gestas de la conquista o la colonia en América y los reyes católicos. Agrega además que el escaso interés "se centra en los períodos menos gloriosos” (2002, p. 21). Argumenta que la escasez de cine épico sobre la conquista tiene su fundamento en que la figura del conquistador recuerda "los aspectos más violentos del tema" (2002, p. 22) y sugiere, sin mayores pruebas, que "las autoridades eran conscientes de lo difícil que era reconstruir el pasado común sin despertar animosidades en alguno de los bandos" (2002, p. 25) ${ }^{7}$. Quizás previendo las potenciales animo- 
sidades, González agregó en su discurso que se celebraba el triunfo de las ideas liberales, "fueran de la ideología que fueran", frente al absolutismo de Fernando VII (Lorite, 2011). Aun así, las caracterizaciones de los antagonistas en estas obras suavizan las condiciones del absolutismo, la falta de liderazgo real y las precariedades en que vivía la mayoría de los súbditos en el fin de la colonia. En Revolución, el cruce de los Andes, San Martín (Rodrigo de la Serna) se refiere a las familias ibéricas como godas, terminología correcta para la época, pero que además diferencia a esa España de la contemporánea. Cuando le recomiendan a un arriero para encontrar la ruta más veloz para cruzar la cordillera, reconoce al hermano de un traidor español y lo increpa, diciéndole "Matucho" o diablo, expresión ocupada por San Martín histórico para referirse a su enemigo. Desde la religiosidad, el cura Hidalgo, en la obra mexicana, también habla del tirano como un diablo. De este modo, el antagonismo se caracteriza como símbolo del mal universal, que no necesita mayor reflexión.

A la vez, las actitudes que tienen los españoles en las obras son de un cierto nivel de cizaña. En El niño rojo, cinta chilena, el Marqués (Álvaro Espinoza) está empecinado en que Ambrosio O’Higgins (Fernando Cía) no acumule más riqueza. Lo espía y desafía y, eventualmente, logrará su ruina. Parte de este amedrentamiento es referirse constantemente a él como un infiel, ya que al nombrarlo inglés, destaca lo protestante en lugar de lo católico. Pese a la corrección de Ambrosio de que es irlandés y, por lo tanto, católico, el marqués no detiene los ataques, sobre todo por el nivel de riquezas que ha acumulado. Prejuicia el mercantilismo de Ambrosio, preguntándose para qué un infiel quiere tanto poder. Esta misma reflexión no ocurre ante el monopolio que tiene la Corona en las colonias. El marqués pareciera estar de acuerdo con que la administración española acumule riqueza, pero no un individuo de otra nacionalidad, incluso si era el Gobernador de Reino de Chile. Más tarde en la obra, el joven Bernardo (Daniel Kiblisky) estudia esgrima y razón con Francisco de Miranda (Rodrigo Soto) en Londres. Entre ruidos de sables, debaten cómo el monopolio español empobrece a las colonias y, además, no enriquece a España, sino a los privados dueños del capital.

Esto es interesante, ya que a través de las obras se pueden vislumbrar dos aproximaciones a la independencia: la de la autodeterminación de los pueblos que llevó a la gesta emancipadora en busca de un llamado a la libertad, igualdad y fraternidad, y otra que es la descripción de los excesos y abusos de la corona. Si bien ambas categorías están vinculadas, esta última, menos destacada y trabajada que la primera, puede ser observada en todas las obras. Por ejemplo, en Hidalgo, la historia jamás contada, parte con la infancia del cura, cuando está estudiando en un colegio de jesuitas y la corona los expulsa de América, precisamente por la riqueza y el poder que habían acumulado. Más tarde, cuando es rector de un colegio jesuita en Sevilla, entra en conflicto con la administración eclesiástica, ya que ellos ven a Hidalgo con recelo por las ideas liberales que enseña, y este, por su parte, los desautoriza porque no están preocupados de cuidar al prójimo. Luego, cuando -como castigo- es enviado de regreso a México, apoya nociones de autodeterminación, sobre todo por las fuertes riendas con que la corona y la Iglesia atan a los criollos. Se destaca en la obra específicamente el impuesto forzado para financiar un ejército contra los ingleses, más el diezmo que cobra la Iglesia, lo que en la opinión del socio de Hidalgo, José Quintana (Juan Ignacio Aranda), está "arruinando a las colonias". El cura Hidalgo (Demián Bichir) responde que por eso se independizaron las colonias inglesas. Esta es la obra en la 
que más se destacan los aspectos de la religiosidad colonial. En casi todas las otras hay personajes de curas que acompañan a los ejércitos y participan de los debates -curas revolucionarios, muy importantes para el período- pero esta película ofrece una mayor reflexión sobre este aspecto, y lo desborda al transformar la tradición en la fuente de libertad.

La obra, que es un gran flashback, explora la detención del cura, quien es excomulgado de la Iglesia y luego entregado a la justicia de los hombres para que salde sus penas ante Dios y la corona. La obra argumenta que la rígida estructura de cobranza de la corona, sumada a la avaricia, el no cumplimiento de la misión, tanto religiosa como de administración central, y la censura a la cultura y la expresión, fue lo que propició al Hidalgo histórico a dar el primer grito de independencia mexicana.

En La Redota: una historia de Artigas la obra uruguaya, Montevideo es el último bastión de la corona en la zona. El general Artigas (Jorge Esmoris), junto con criollos, indígenas y negros, funda un campamento de independentistas de la banda oriental del país y del Virreinato del Río de la Plata tras el levantamiento del sitio de Montevideo. El protagonista de la obra es un soldado español desertor que se convierte en espía del triunvirato del gobierno central de Buenos Aires llamado Guzmán Larra, (interpretado por Rodolfo Sancho, hijo de Sancho Gracia, el productor general de Lusa Films). Él relata la debacle de una Buenos Aires independizada, la cual describe como traidora. "Un soldado realista aquí ya no tiene sentido. Ya no tiene bandera", propone al comienzo de la obra en una voz en off que será característica de toda la obra, con un tono reflexivo y un tanto nihilista. Más adelante, ya establecido en el campamento denominado La Redota, reflexiona: "Oro y plata venimos a saquear y a cambio le entregamos la sangre de sus propios hijos", seguido de "Qué vinimos los españoles a hacer aquí si no hay la plata de Potosí, ni el oro de México, ¿qué extraemos de aquí? Vinimos a enriquecernos y a retornar". La motivación del personaje no es nacionalista -retornar las colonias a la corona o defender el nombre de España- sino personal. Desea ser perdonado por desertar para poder volver a España, donde está su amada. Pese a esto, y casi sin notarlo, va empapándose cada vez más del nacionalismo de La Redota. Esta misma película comienza con un intertítulo que dice "Año $1800 \ldots$ y poco, españoles, portugueses, ingleses, holandeses y franceses aún matan...aún mueren, por dominar los pueblos de Sudamérica". Poco después, leemos también "Aprovechando que las invasiones napoleónicas han puesto a Europa patas arriba, surgen, en las colonias saqueadas, los que quieren terminar con el yugo". Nuevamente, la idea de saqueo como justificación económica aparece en los fundamentos, pero ya no solo son españoles, sino europeos. La idea de seguir al rey y no al país se reitera en varias obras. Sin embargo, en La Redota es donde más aparece. Por ejemplo, al redactar un petitorio de ayuda, corrige "España no, la madre patria, que es más respetuoso" tras nombrar a Fernando VII, describiéndolo como "nuestro rey", Artigas agrega "que Dios guarde". Esto es interesante, porque sobre todo en las etapas tempranas, las independencias no son en contra del absolutismo de rey como sugiriese el ex presidente español González, sino más bien por su ausencia. Más tarde en la obra, se sugiere que servían a los borbones porque creían que era el mejor sistema. Pensaban que solo había una religión y que los demás eran infieles. Habían creído en un gobierno central y poderoso, y creyeron que los conquistadores tenían más conocimiento que los indígenas, pero no conocían otro sistema. Ahora deben cambiar todo esto por la nación que se 
imaginan. Así, el cabildo de La Redota invita a pensar en un nuevo futuro y, como espectadores, nos cuestionamos si realmente llegó o si se debe continuar construyendo siempre. En esta obra no hay un antagonismo evidente hacia los españoles, sino más bien hacia los portugueses, quienes son mencionados como violadores de acuerdos, ya que tras el armisticio, debían dejar la banda oriental y no lo hacen. Se les dice traidores, verdugos, salvajes, violentos, y son representados por una cuadrilla que es detenida y torturada. Cuando ven al espía español y le dicen que son europeos como él, él se identifica: soy el Marqués Ricardo de Alburquerque. Así, se ejemplifica una visión de dos mundos; los europeos por una parte, que son iguales, y por otra, menos clara, los criollos, indígenas y quizás incluso negros. La obra, montada con cortes abruptos y entrecruzando audios con imágenes, deja estas palabras en el aire. Si bien el personaje del soldado, espía y periodista encubierto es ficcional, esta es la única obra que opta por un español de protagonista, y es un hombre conflictuado.

En Joaquim, como de alguna manera sucede en La Redota, no es realmente el imperio español el enemigo, sino el imperio portugués, bajo el mando de María I, reina de este país. Ante la insurrección llevada a cabo por Joaquim, por la independencia de Mineira, primer intento brasilero, fue decapitado y desmembrado y las partes de su cuerpo distribuidas por el territorio. La película que comienza narrando esto en la voz del protagonista ya sentenciado y asesinado, es realmente un gran racconto a los días que llevaron a la insurrección, el despertar libertario del protagonista y la percatación de la falta de integridad de la administración. Nos muestra la violencia con que se trataba a los contrabandistas de oro y la corrupción de los administradores portugueses -ladrones en uniformes- como los describe el protagonista. El oro domina la vida del siglo XVIII en este lugar alejado del poder central, y para Joaquim (Julio Machado) el éxito de su misión de encontrar nuevas tierras con este material o piedras preciosas, posibilitarían su ascenso en la estructura militar, pero también la compra de Negra (Isabél Zuaa) la esclava del que está enamorado y que se ha fugado tras una violación. El sufrimiento y miseria desprendido de la explotación de las riquezas de la tierra, en las ciudades y también los sectores rurales, así como el cuestionamiento a los muy altos impuestos, son la tónica en la obra.

En Bolivar, el hombre de las dificultades, es difícil identificar las políticas o motivaciones de la independencia. La película parte cuando ya ha caído la Segunda República y Venezuela se encuentra dividida. El prócer, exiliado en Jamaica, defiende la noción expresada en la Carta de Jamaica -que es solo nombrada en la obra, mas su contenido no es explorado- en tanto que los ingleses no desean apoyar el proceso de independencia meridional. Bolívar (Roque Valero, actor y político chavista) increpa al gobernador de Jamaica y le pregunta si “¿va a pasar de la posibilidad de ayudar a liberar a la mitad del mundo?” Pero el imperio inglés no quiere antagonizar al español, que era su aliado en una guerra contra Francia y las fuerzas napoleónicas. Nada se habla de los españoles fuera de que el personaje del Polaco (Jorge Reyes) ha sido contratado por el rey de España para asesinar al Libertador. Pareciera más bien que el deseo de autodeterminación proviene de no querer estar entre las luchas de imperios a los que poco o nada les importan sus colonias.

En el caso cubano, donde la película no representa las primeras independencias como describiese Ferrada, sino la infancia de José Martí entre sus 9 y 17 años (1862-1870, casi 50 años después de los primeros intentos de independencia del continente), el ejército español 
es iracundo y desmedido. Por ejemplo, un soldado es pasado a llevar por un porteador negro que está entrando la mercadería al bodegón de don Salustiano (Manuel Porto). El soldado lo abofetea, le grita que se arrodille y le pida perdón. A esto, el interpelado responde que es libre y cubano: "España es la que debe disculparse ante nosotros" con cierto recelo, responde un bijirista en defensa del hombre, nombre dado a los defensores de la independencia cubana. El soldado lo agarra, lo apunta con una pistola y lo amedrenta, gritándole que si no exclama "viva España", le cortará la lengua. Ante esto, Salustiano silencia a todos quienes están en el bodegón, bijiristas y gorriones, nombre dado a los voluntarios cubanos que defendían a España. Dice que es de Galicia y ama a España, y hace brindar por Cuba y su país natal. Salustiano cuida a Martí niño, le da trabajo y lo ayuda a continuar en la escuela. Defiende a los cubanos y les da asilo, y detiene el maltrato a los negros, sean libres o esclavos. Por esto, los voluntarios y el ejército toman represalias y destruyen el bodegón. Años más tarde, tras la libertad de prensa y durante el estreno de la obra de tonos revolucionarios Perro huevero, aunque le quemen el hocico en el Teatro de Villanueva, los voluntarios no solo la interrumpen, sino que disparan contra el público, matando a varios espectadores. Además, se toman con violencia las calles de La Habana por varios días, obligando a fuerza de violencia a gritar “ ¡viva España!” y humillando o asesinando a quienes por allí pasaban y llevan a cabo la ejecución pública del revolucionario que se escondía en casa del profesor Mendive (Julio César Ramírez). El ejército de voluntarios es desmedido en su violencia, irracional, y letal. Salustiano a su vez no reniega de su ascendencia, pero es sobre todo un humano y defiende a quienes están siendo abusados. Este contraste entre los personajes españoles suaviza la brutalidad del ejército y la desidia de la corona.

De este modo, la voz de los pueblos latinoamericanos parece levantarse ante unas coronas engolosinada por las riquezas de América, las que obtienen mediante saqueos, cobros de impuestos y un monopolio forzado. Salvo en Martí, y marginalmente en Revolución, la crudeza de las guerras de principios del siglo XIX no domina las representaciones; estas no son realmente cine bélico. En cambio, las caracterizaciones de españoles y/o europeos representan un mal arcano e incuestionable y, por lo tanto, sobre el cual no hay una reflexión posible. Así, se normaliza a la vez que se despersonaliza, se vuelve una lucha de represores contra reprimidos, bien contra el mal, los españoles y portugueses se vuelven arquetipos, no naciones con pasados terribles de los que hacerse cargo.

\section{La autodeterminación: la voz a los victoriosos}

En los procesos de autodeterminación que trabajan las obras, se niega el absolutismo, la tiranía y la invasión napoleónica. Se mencionan opciones de gobierno como triunviratos y directores supremos, y se señala el federalismo, es decir, algunas de las maneras en que las ciudadanías de América Latina se organizaron. Sin embargo, son más potentes las explicaciones y reflexiones sobre lo que deben ser las naciones que lo que hoy parece ser el pragmatismo político de cómo administrar. Como dijese González, celebran "el triunfo de la ciudadanía en América Latina” (Lorite, 2011). Por ejemplo, en Revolución, el cruce de Los Andes, los intertítulos describen cómo los pueblos de América "casi al unísono se levantan y forman sus propios gobiernos". En la obra, se hace alusión a los problemas entre los 
gobiernos de Mendoza y el central de Buenos Aires, pero el énfasis está en otra reflexión. Con un extenso montaje de cómo se trabajó para crear el Ejército libertador de Los Andes -de uno 5200 hombres- escuchamos al general describir las inequidades y violencias de los españoles. Luego dice: "Crearon un ejército del barro mismo para el beneficio de todo un continente". Mucho más tarde en la obra, el general envalentona a quienes lucharán diciendo: "Trecientos años de masacre y barbarie tiñen nuestra tierra de sangre". En ambas escenas, así como en múltiples más, la ciudadanía americana no es solo a quien se interpela, sino quienes están en escena.

En esta obra, el impactante y muy cinematográfico Ejército Libertador está conformado por criollos con estudios militares, hombres de campo y tierra que se reúnen con herramientas de trabajo, y mujeres que confeccionan los uniformes y aperan lo necesario. También hay escuadrones de libertos y mulatos. Es más, el general le pide al cura que los acompaña que bendiga todo lo que pidan los muchachos del octavo regimiento y los deje hacer sus brujerías, explorando así, aunque superficialmente, la libertad de culto en el ejército. Al mismo tiempo, en una escena, el Sargento Blanco (Alberto Morle), a cargo del escuadrón, juega ajedrez con San Martín, quien le recuerda por qué luchan y le pide valentía a él y su tropa, además de regalarle el tablero. Discuten cómo la libertad puede ser solo una palabra, pero por lo que lucha el ejército es "un profundísimo anhelo" de ser todos hermanos. Así, desde el comienzo mismo de la obra, los negros, que tienden a estar invisibilizados de estas narraciones del pasado del sur del continente, tienen agencia, voz y acción importantes, tanto así que es el único escuadrón individualizado. La película plantea como el ejército libertador nace de la precariedad, de un lugar pobre, entre ranchos humildes que dan todo, creado por gente también pobre, dando también un marcador de clase. Esta nueva ciudadanía que incluye a todos traspasa los límites nacionales cuando el viejo Corvalán (Juan Ciancio) responde a la pregunta de cómo era el padre de la patria diciendo “¿Qué es para usted la patria?” y, ante el silencio, agrega: “¿Padre de qué patria?: ¿de la Argentina, del reino del Chile, del Perú, de todas juntas?” Así, lo inclusivo sobrepasa aspectos étnicos o socioeconómicos e incluye reflexiones fronterizas.

En un caso similar, la libertad en Hidalgo se expresa reflexivamente y en la práctica. Aquí, las injusticias de la corona y la administración colonial se resumen en el trato a los indígenas. No se les permite entrar a la misma iglesia que los blancos y no se les da libertad para expresar su religiosidad. Se les mata por brujos, se les asesina a sus animales y su sustento laboral, se les destruye su trabajo y se les incendia su iglesia con miras a que bajen sus sueldos y trabajen como esclavos de un sistema represor. El cura los apadrina, los deja entrar a cualquier espacio religioso, les enseña cómo producir artesanía de forma más masiva que para su propio consumo con el fin de poder venderla, los acompaña y participa en sus desfiles religiosos. Con respeto y dignidad empodera a los indígenas marginalizados Así mismo, la película busca, aunque de forma menos evidente, otorgar libertad a las mujeres. Va desde ridiculizar la banalidad de tener un vestido igual al de María Antonieta hasta darles roles en obras de teatro e incentivarlas a tomar y bailar, vislumbrando incluso atisbos de libertad sexual. De este modo, la cinta está basada en la colonia de México antes del grito de Dolores (1810), y explora el miedo al eventual protectorado francés en México mediante nociones de libertad, igualdad y fraternidad entre indígenas y criollos, entre hombres y mujeres y entre clases sociales. 
En Martí, el ojo del canario, los valores revolucionarios están presentes en elementos culturales. Observan luto en la escuela y en el bodegón cuando muere Abraham Lincoln en Estados Unidos, país ya independizado y del cual se admiran los valores independentistas. La ópera de Giuseppe Verdi Nabucco es mostrada múltiples veces mientras la compañía italiana se está presentando en la isla. Esta tragedia lírica habla de los esclavos hebreos que buscan su independencia y de los deseos de paz en este proceso bélico. La narración bíblica es fácilmente homologable al caso cubano, tal como lo hicieron los italianos en su lucha de independencia en la década de 1840, lo que ya había hecho de la obra un símbolo de libertad, independencia y emancipación. De hecho, uno de los despertares del joven Martí es cuando acompaña a su padre a trabajar a las haciendas de Hanabana. Como trabajador de la corona, el padre va a la zona a acabar con el tráfico de esclavos. Sin embargo, no lo logra debido a la corrupción reinante. El joven Pepe hace amistad con el viejo esclavo Tomás (Enrique Lázaro Piedra), que le muestra la ceiba "sagrada y sabia". Hermosas tomas de animales y naturaleza contrastarán luego con las antinaturales imágenes de familias completas de negros siendo traficadas hacia la esclavitud. De este modo, vemos a los guajiros, campesinos locales, a las familias de clase alta, a los traficantes de esclavos y a enormes cantidades de negros en condiciones de la más inconcebible violencia. Estas realidades marcarán al joven Martí y señalarán quiénes son la ciudadanía más allá de las ciudades. Así, en esta obra, la independencia se lucha para guajiros y esclavos, por libertades de expresión y por la dignidad del pueblo cubano.

O’Higgins, el niño rojo posee una doble reflexión sobre quienes componen la ciudadanía. La obra también está basada en la infancia del prócer, desde su nacimiento en 1778 hasta más o menos 1809, incluyendo su infancia temprana en una casa para niños huachos en Chillán, algunos años en una comunidad Mapuche, la Escuela de Naturales que los jesuitas tenían para la élite Mapuche, la escuela en Lima, donde se codeaba con la más alta aristocracia virreinal y su educación en Londres, donde conoce a Miranda, un venezolano que luchó en la independencia de EE.UU. y reunió a futuros líderes del continente de Colombia, México, Perú, Argentina y Chile para conversar y debatir política en su casa en Londres. En la obra, se describe este grupo como la logia de caballeros racionales, ya que es la razón con la que se oponen a la tiranía, razón que debe ser acompañada de pasión, cuidando "el fuego sagrado de la libertad". Fuera de hablar del monopolio económico, los representantes latinoamericanos reflexionan sobre cómo los valores de libertad, igualdad y fraternidad no deben ser ideales, sino ser tratados como necesidades humanas que satisfacer. Miranda dice que toda América debe ser una gran patria: "Colombeia". Por su parte, Ambrosio describe a este grupo, con sus ideas y su líder, como el "enemigo más peligroso de la corona" porque enfrentan a la corona con el apoyo inglés, unificando a América y convirtiéndola en más que territorios individuales, en una "potencia", como dijese Artigas en La Redota. De este modo, el joven Bernardo no solo defiende sino que además pertenece a diferentes clases socioeconómicas a lo largo de su vida: estrato bajo al principio con contacto directo con pobres y marginados, con el mundo indígena rural y de élite, con la hacienda siendo el patrón, luego con religiosos franciscanos, con los criollos aristócratas y después con la ilustración europea; una escala muy amplia en la sociedad de su tiempo y O'Higgins las puede representar a todas. 
El clímax de la obra ocurre cuando Bernardo recuerda las enseñanzas de perseverancia y espíritu guerrero aprendidas de su madre postiza y nodriza Mapuche (Gabriela Arancibia): "Kisu ngünewün, Peñiwen iñchiñ, Trürümuwaiñ", dice el futuro prócer. De los ideales de libertad, igualdad y fraternidad, sincretizados con la cultura Mapuche, el joven Bernardo aparece en un flash forward envalentonando a una tropa de campesinos e indígenas. Se revela contra su padre, el virrey y la corona. Toda la secuencia de desprenderse de las creencias de su padre y convertirse en el revolucionario está sostenida por la música de un trompe, instrumento tradicional del pueblo Mapuche. Por lo tanto, aunque la secuencia ocurra en Londres, deja en claro el pueblo por el que se luchará.

Bernardo también afirma en varias partes que liberará a su madre de las duras condiciones de género que existían en la colonia, que nuevamente están representadas por una detallada puesta en escena. Por ejemplo, cuando Isabel Riquelme (Ana Burgos) se prepara para su matrimonio forzado, la estructura del vestido es mostrada de tal manera que nos expresa su aprisionamiento en la sociedad; el miriñaque actúa cual jaula (Bossay, 2014). Así, la ciudadanía de la obra chilena incluye desde niños abandonados por enfermedades y discapacidades incluyendo también mujeres e indígenas.

En Bolívar, el hombre de las dificultades, el prócer viaja a Haití para buscar el apoyo de esta recientemente liberada nación. Aquí, se pone en evidencia la carencia de conciencia al no incluir el fin de la esclavitud en los llamados de independencia de Venezuela. De hecho, cuando se reúne con el presidente Alexander Petion (Gilbert Laumord), se encuentra también con las otras facciones venezolanas que estuvieron obligadas a escapar tras la caída de Caracas. El gobierno, dirigido por y para afrocaribeños, pone en tela de juicio las divisiones internas de los venezolanos, que no están realmente exploradas en la obra, y también sus políticas generales, como no cesar con la esclavitud. En un improvisado cabildo venezolano en Haití, la obra parece sugerir que Bolívar busca la libertad de los esclavos, más por el apoyo haitiano que por creerlo justo, y detona una acalorada discusión entre los detractores de este principio y quienes están de acuerdo en que la revolución sin la libertad de todos los esclavos no se puede llamar revolución. Esto revela, aunque de una manera utilitaria, un concepto de ciudadanía más amplio.

Una haitiana invitada a la cena en la casa del presidente también revela el profundo machismo en las nociones de independencia y de Bolívar mismo que en la película, es un mal galán que tiene más sexo que conversaciones del futuro. Bolívar ofende a las mujeres que lo ayudan y aman, como sus generales ofenden a los haitianos por ser negros. En la cena el presidente pide "Libertad para los esclavos". "Igualdad para los pardos", agrega Manuel Piar (José Luis Usech), cuyo origen de casta ha sido debatido por la historiografía, pero que probablemente fue un general mulato. "Libertad e igualdad para las mujeres, participación en todos los sectores de estas nuevas repúblicas", agrega la invitada Jeanne Bourvil (Camila Arteche). De este modo, la ciudadanía por la que se debía luchar era una más compleja, que la imaginada en la primera etapa de la revolución.

En Joaquim, parte del despertar de conciencia viene de comprender el violento trato ante grupos subalternos. Negar el derecho a un plato de sopa de un niño indígena, o del abuso sobre el cuerpo de Preta, por la corrupción administrativa. Por otro lado, por una gran parte de la película seguimos la misión de búsqueda de oro de cinco hombres; el esclavo negro de Joaquim, João (Welket Bungué), el indígena Inhambupé (Karay Rya Pua), el 
protagonista criollo, hijo de padre portugués y madre brasilera, y dos empleados más del ejercito portugués, siendo uno el mestizo Januário (Rômulo Braga) y el otro un portugués con aires de grandeza Matias (Nuno Lopes). En sus dinámicas vemos la compleja segregación racial que está operando en la sociedad. La obra nos muestra el sincretismo de las naciones americanas en acción cuando en vez de estar en el fondo de una escena, João e Inhambupé cantan canciones de sus pueblos, las que convierten en una, mezclando ritmos y locuciones, mientras miran en dirección a un futuro simbólico.

Estas nociones se extienden cuando Joaquim es secuestrado por un grupo de esclavos rebeldes, que se han escapado de las prisiones y tratos deshumanizantes. Entre ellos está Preta, que casi al final de la obra lo deja ir, no sin antes decirle que preta es un color -literalmente negro- y que su nombre es Zua, y que nunca más un blanco abusará de ella. Inspirado de este acto lleno de agencia y control sobre su futuro, el protagonista cae en cuenta del viaje que ya había iniciado, hacia el primer intento de independencia, el cual buscará que todos sean tratados igualmente, como en EE.UU. La evidencia del amor no correspondido gatillará una revolución.

En el cabildo en La Redota -obra con más reflexiones de corte político-, ante la idea de negociar con Río, se afirma que no lo pueden hacer con los portugueses porque ellos son españoles. A esto, un personaje responde: "Éramos españoles, ahora podemos ser lo que queramos, ingleses, franceses". Es solo Artigas quien sugiere que pueden ser americanos. Ante la duda de quién será el rey, surge la propuesta de una república. Artigas dice, en un close-up y con una suave música épica, que están "rodeados de muchas provincias que padecen lo mismo". Agrega que "juntos, podemos ser un ejército continental, somos una potencia". En otro momento, el general también argumenta: "Aquí naidens es más que naidens", y la obra lo convierte en un lema del bicentenario.

Se suma también una compleja representación de indígenas, campesinos y negros, pero no solo desde el espacio característico de la masculinidad, sino con varias mujeres. Artigas tiene una pareja indígena, con quien tiene un hijo. Vemos a mujeres negras construyendo La Redota, de igual con hombres, casi al final de la obra, una cantora popular defiende a toda la identidad oriental contra un payador porteño. "Tenemos que seguir, tenemos que ser constantes, si seguimos los ideales, seremos gigantes" canta la payadora, resumiendo el sentimiento de orientales, incluyendo a todos y todas.

A través de la puesta en escena, específicamente los cuidados castings, vestuarios y maquillajes de las obras, se logra dar agencia y voz a varios y diversos sujetos subalternos. Así, estas obras representan al variado pueblo latinoamericano. Aparecen indígenas hablando sus propios idiomas; esclavos siendo liberados, decidiendo luchar por las nuevas repúblicas con sus propias culturas y autogobernándose; criollos intentando el diálogo comprendiendo otras realidades y empatizando con ellas; mestizos y campesinos; mujeres obrando por las independencias, educándose, liberándose (aunque en menor grado que todos los otros grupos subalternos). Como bien dice el personaje de Artigas en La Redota:

La verdadera riqueza de esta tierra es esta gente, esta mezcla, este caos, la multitud de ideas, de contrastes, de deseos confusos, de sueños. Pero, cómo juntar tantos sueños, cómo armonizar todo este caos, todos estos deseos, sin la fuerza, sin derramar sangre, sin matarnos. 
La soberanía americana por la que se lucha entonces es una de igualdad, virtud, respeto y libertad.

\section{Las vidas privadas}

Las poderosas ciudadanías representadas en las películas de la colección Libertadores son unificadas por líderes fuertes. Todos los guiones deciden contar las películas desde individuos -hombres y en su mayoría criollos-. Sin embargo, lo hacen problematizando sus vidas privadas y explorando las cargas personales de los próceres. Como sugiriesen las propias noticias de TVE, muestra a un Hidalgo "humano, capaz del error, como todos; tal vez Hidalgo sin bronce ni pedestal como en pocas, poquísimas ocasiones lo volveremos a ver" (2009), este aspecto era esencial para Sancho Gracia (Morales, 2018). Vemos a los líderes con sus pasiones, y obsesiones, un poco trastornados. Son heroicos, pero humanos. Sus representaciones no son las icónicas sobre caballos estáticos de estatuas ni marmoleados sino con sus dudas, deseos, placeres, dolores, amores y familias. Es desde estos rasgos íntimos y personales, que aparecen las actitudes humanistas artísticas de los prohombres, y algunas de las exploraciones más poéticas de las obras.

Por ejemplo, el espíritu humanista de Hidalgo está constantemente presente. Su casa en Villa de San Felipe -actual San Felipe Torres Mochas- es conocida como la pequeña Francia. En ella la libertad domina el quehacer cotidiano. Fiestas con músicos que tocan canciones prohibidas, prácticas de obras de teatro también prohibidas, como la adaptación de Tartufo o el impostor, de Molière. Asimismo, se llevan a cabo osadas fiestas donde las mujeres no solo pueden cantar, actuar y bailar, sino que explorar sus sexualidades y él también tiene una vida sexual activa, que lo mete en problemas, pero también lo hace pedir perdón, a quienes daña, no a la iglesia. En su afán de crear conciencia independentista o al menos libre pensante, se da cuenta que él también ha sobrepasado su cargo y abusado de lo que tiene, pidiendo más de lo que debería a sus amigos y fieles. La obra de teatro ha sido una metáfora de lo que él vive en lo privado. El cura humano, con hijos y parejas, que defiende a quienes no tienen voz, los ayuda a encontrar dignidad en un sistema que se las arrebató. Es además, un actor y dramaturgo que será capaz de tomar armas.

En el barco de regreso a Venezuela desde Haití, Bolívar pasa a buscar a la astuta y enamorada Pepita Machado (interpretada por la cantante y actriz Samantha Dagnibo) quien ha logrado escabullir a través del Caribe una imprenta. Cuando el capitán del barco le pregunta qué han pasado a buscar a Saint Thomas, Bolívar, demostrando su icónica labia -que en la cinta está un tanto abusada- dice "artillería para el pensamiento" es una imprenta con la que publicará el decreto sobre la libertad de los esclavos. Aun así, en la obra veremos las múltiples dificultades que tuvo que superar para llegar a este momento, tanto políticas, familiares como privadas, aunque desde el guión pareciera que él se metió en la mayoría de los problemas.

En Martí, el ojo del canario, se representa la infancia y adolescencia del revolucionario dividida en cuatro segmentos que son distintos despertares del joven: Abejas, Arias, Cumpleaños y Rejas. Desde pequeño tiene una amplia dotación humanista que se ejemplifica con la traducción de Lord Byron y su trabajo en la ópera mientras están de giras las com- 
pañías italianas. Tiene su propio periódico "Patria libre", escribe obras de teatro y poemas cómo Abadala (1869). La escritura de cartas y la defensa de la razón mediante la prosa están presentes en varias partes, y será también lo que eventualmente lo lleve a la cárcel. Lo personal se convierte en lo poético, cuando mediante la palabra comienza a explorar la autodeterminación, la libertad, y a denunciar las injusticias que sufre la isla, así como también los aspectos personales de su familia y la relación con el padre, a quien tendrá que eventualmente renegar.

La obra además alude con metáforas visuales a la propia obra de Martí, que tanto como el apóstol independentista cubano, es además uno de los más reconocidos poetas del continente. Por ejemplo, el mismo título de la obra hace referencia a un segmento de un poema que habla sobre la infancia del joven Martí: "Yo pienso cuando me alegro/ como un escolar sencillo/ en el canario amarillo,/ que tiene el ojo tan negro!” En estos Versos sencillos (1891), se explora la fusión de hombres y naturaleza en de la isla, cómo también hará en "Abejas" la película. También hará esto con los segmentos sobre la muerte de la hermana. El también niño Bernardo O’Higgins, comparte con Martí, un ávido pasar por instituciones que lo educan y le entregan diversas visiones de mundo. En ellas aprende a dibujar y pintar, sobre música, matemáticas y ciencia: un hombre humanista. La interesante manera en que está filmada la colección epistolar entre el prócer y su madre y padre -con el actor narrando a cámara las palabras de las cartas- invita al público a conectar con las propias palabras de O'Higgins, en donde se habla de amor, desafíos, y logros académicos. La incorporación de filosofía y música Mapuche para los segmentos en que enfrenta grandes desafíos nos permite ver también una interpretación de la cultura e identidad chilena contemporánea que incluye en la narrativa no solo al criollo.

En Joaquim, la vida privada está apoyada de literatura y música que inspiran al protagonista, sin embargo, es más importante el rol del agua como metáfora de la historia. La figura de criaturas que viven de lo vivo, como piojos, sanguijuelas y pirañas, crean una noción del imperio devorando a la colonia. La constante sumersión en busca de oro, vuelve esta fuente de vida en un lugar de opresión. De modo similar, es el reflejo en movimiento de Joaquim en un río, que lo hace distorsionar la visión de mundo que tenía y comenzar el viaje hacia revolucionario. Quizás más evidente es el comienzo de la obra, donde similar a Hidalgo, vemos el castigo ante el levantamiento, no éste mismo. Es esta la única escena en que llueve, y además la noche no está acompañada de fuego o luz de vela como en el resto de la película. En cambio, las gotas que primero solo se escuchan pasan a convertir el lente -o la pantallaen un velo que imposibilita la percepción clara de la cabeza decapitada, que pese a toda razón, nos habla de ultratumba advirtiéndonos del resultado del levantamiento, de religión y clase socioeconómica, pero aun más, de como su historia se contará en el futuro. La lluvia visibiliza el método de rodaje y exhibición, y materializa así, la creación historiofotica desde su potencial estético sonoro, además de destacando los martirios de los libertadores.

La película argentina y la uruguaya utilizan estrategias similares de representación del pasado. Cuentan la vida de los respectivos líderes desde los ojos de personas que los conocieron. En Revolución, es a través de Manuel Corvalán, interpretado por Juan Ciancio cuando niño y León Dogodny de anciano. La obra comienza cuando el cuerpo de San Martín está pronto a volver del exilio en París, tras su muerte, y un periódico quiere presentar a sus lectores, cómo era el padre de la patria. Desde la experiencia del mocito Corvalán, aparece 
un hombre sumamente obsesivo, gran estratega, meticuloso, guardián de quienes ofrecían su vida por la causa, pero a la vez precipitado por llegar a dónde cree debe estar, incluso poniendo su propia vida en riesgo. Desde la admiración del niño, la película lo muestra siendo general, padre y esposo, en mucho dolor y solo. Un San Martín visceral, enfermo, pero jamás rendido.

Por su parte, Artigas en La Redota es presentado a través de la experiencia, dibujos y notas de Guzmán Larra (Rodolfo Sancho). Pero aún más importante, éstas son utilizadas por el pintor Juan Manuel Blanes quien es comisionado por Máximo Benito Santos, militar y presidente del Uruguay, para pintar un cuadro sobre el prócer, casi setenta años después. Esta es la película que más eficientemente refleja las sutilezas de la creación histórica y la fuerza dialéctica que tiene el presente en cada imagen. El pintor Blanes de la cinta se basa en los dibujos de Guzmán Larra que recibe cuando pide ayuda al presidente por falta de materiales, ya que busca evitar errores de representación. Santos le dice que los invente. Agrega, usted "está pintando la patria, creando la amalgama de la nación". Lo que hace el pintor es crear una imagen dentro de La Redota, en dónde Artigas está rodeado de gauchos, campesinos, indígenas, negros y mujeres. Santos la rechaza preguntando quiénes eran esos "piojosos y gente ordinaria" y obliga a Blanes a pintar una nueva obra, que represente correctamente al padre de la patria. La segunda versión será la que eventualmente se titulará Artigas en la puerta de la Ciudadela (1884), que cómo describe la película se puede encontrar en escuelas, oficinas públicas, embajadas y consulados. Así, la película corrige el imaginario decimonónico, brindándole una raigambre del bicentenario.

De este modo, la película nos muestra un Artigas conflictuado por su propio presente, decidido a congeniar muchas versiones distintas de libertad, nación y orientalidad. Pero a la vez sobrepasado por las constantes peleas, traicionado por sus compañeros y obligado a traicionar a sus amigos por el ideal mayor. En una escena grita a todo pulmón de frustración frente a una catarata -estos gritos de frustración aparecen en todas las películas- en otra recibe a su hijo en brazos y lo mira con la ilusión del futuro y el riesgo del presente. Sin embargo, estos aspectos humanos y personales están invisibilizados en la experimentación temporal con que la obra decide representar a quien creó el cuadro más famoso del padre de la patria uruguaya. Poniendo en vez como protagonista a la imaginación, la reconstrucción histórica y la representación de los próceres de un período del cual, como sugiriera Ipiña, tenemos un escaso conocimiento sobre su visualidad.

De este modo, la exploración de la veta humanista y los amores de los libertadores ayuda a examinar sus lados más privados y sensibles. Desde estos aspectos, que tienden a ser los menos basados en datos históricos y más dependientes de la interpretación, también vemos las exploraciones más poéticas de los propios directores de las películas. De este modo las emociones de los próceres se convierten en los compromisos de los directores y sus visiones de la historia. Sin embargo, es importante considerar que las obras están pensadas como unitarias, y en base a figuras fuertes. Además, se decidió no interconectarlas, por lo que entre ellas no se vinculan actores, eventos, ni otros guiños a procesos en común. Todo esto, sumado a que no todas representan los mismos años ni fueron realizadas simultáneamente, dificulta la narración de una historia conjunta en el macro de los procesos de las independencias en América Latina. Son más bien narrativas sobre libertadores de países individuales, no de regiones completas. Esto es interesante ya que las independencias la- 
tinoamericanas no podrían haberse luchado sin los apoyos de otras naciones, sobre todo en el cono sur. Esto efectivamente está mencionado en las obras sobre Artigas, San Martín, O’Higgins y también en la de Bolívar en Centroamérica y el Caribe, pero las situaciones de tal solidaridad continental están más bien minimizadas y hay que tener un ojo astuto para ver a O'Higgins en la obra argentina o a los latinos en la chilena.

Todos los Libertadores vivieron reconocimientos difíciles y disputados tanto en vida como en muerte y sus decesos en exilio prueban las diferentes facetas de este convulsionado período. Como sugiriese Sancho Gracia "ellos fueron los precursores de la libertad de Latinoamérica, aunque la mayoría de ellos no llegaran a verla” (Vertele.es, 2009). Este sacrificio por la patria, las epopeyas históricas y personales y los desafíos culturales y políticos que estos hombres representan, logra escaparse de la trampa hagiográfica del líder que no comete faltas ni tiene dudas, y nos permite hacer reales a los próceres por al menos una hora y media, trayendo una interpretación del pasado al presente, que es a la vez un comentario de valores a luchar por hoy.

\section{Conclusiones}

La colección Libertadores, trata de las facetas humanas de los libertadores, es decir desde los individuos y sus viajes de vida, militares, y/o políticos. Esto centra necesariamente las películas en solo una de las múltiples vías que se gestaron en los procesos de independencia. Así mismo, se trabaja desde casos aislados en vez de ideales regionales o bolivarianos; esta estrategia permite que las diferencias entre cada caso sean tan grandes que España también puede entrar en el mismo conjunto de hispanidad, de una misma lengua, de desafíos similares. El documento oficial de Wanda sugiere que todos los Libertadores

Tenían en común la idea integradora de una gran patria americana, basada en dos grandes ideas que, en nuestra era de la globalización, tienen una evidente actualidad y vigencia: La fraternidad de sus pueblos y la libre relación con los del resto del mundo, fundada en el progreso material, político, social y cultural (Wanda, 2010).

La representación de la fraternidad está presente y es constante, y el progreso material está ciertamente asociado a la cultura, teatro, música, arte y poesía. Sin embargo, el enemigo común no es el imperio español, aparecen otros países europeos de carácter imperialista, dónde los múltiples conflictos interregionales se dejan entrever, y las dudas de los propios próceres pesan sobre los hombros del progreso que llegará no a Latinoamérica sino a Iberoamérica.

De este modo, los enemigos están caricaturizados, son villanos más que seres con creencias de una época y un ethos. Las naciones evidentemente antagonistas, Portugal y España, engendran desertores ante la realidad del continente y sus procesos independentistas, quienes pasan a apoyar o liderar las causas. Al mismo tiempo, varias de las obras mencionan choques de personalidad, o desencuentros ideológicos y disputas de administración y liderazgo entre estos libertadores y otros generales, ideólogos y líderes. Quizás aquí habría 
que recordar -al margen- que las actuales naciones no se crearon en las independencias. Nuestras fronteras, en algunos casos aun en disputa, se continuaron cristalizando hasta finales del siglo XIX. La mayoría de estas obras no marcan estas dificultades tempranas, muchas de ellas no hacen siquiera alusión a las diferentes facetas internas dentro de cada una de las naciones. Pese a la decisión de basar las obras en individuos, los valores representados no son de culto a la persona, sino de comunidades.

Por su parte las nociones que detonan las independencias tampoco tienen lugares protagonistas, se verbalizan más que mostrarlas en su fuerza visual. Así, se enuncia el absolutismo como enemigo, aunque las obras persé no lo hacen. Se habla de la crueldad y de la codicia, pero la primera solo se ve en función de la segunda y esta a su vez aparece muy poco, o en general solo se enuncia. En cambio, presentan lo que unifica: el trato respetuoso entre quienes conformamos América. La autodeterminación defiende la fuerza en números, la hermandad y amor al prójimo. Postulando así, que estas maneras de pensar la identidad de las independencias son también nuevos modos de pensar la identidad contemporánea. De hecho, la colección ha resignificado en los Bicentenarios diversas ideas sobre el pasado del continente, para proponer así, una nueva identidad regional en miras a un mundo globalizado, inclusivo, no discriminatorio, a lo menos desde los guiones. Este es definitivamente uno de los marcadores de cine de cruce o "crossover". En los valores de las obras vemos la lucha por la libertad para todos, con profundo respeto de las diferencias y dignidad. Los libertadores tuvieron en sus vidas cinematográficas los esfuerzos por defender a mujeres, indígenas y negros, y todos los sincretismos étnicos que nacen de nuestras sociedades. Otorgando igualdad étnica y de género, global más allá de lo regional. Si bien están ausentes las orientaciones sexuales e identidades de género LGBT, y en menor medida también lo están las diferencias de clases, la representación no racista u no binaria entre géneros es una progresista manera de mirar el continente en sus bicentenarios, visibilizando la historia de estas relaciones. Los sincretismos de siglos son puestos como valores. $\mathrm{Al}$ apoyar las efemérides de las independencias, estas películas entretienen e ilustran. La variada gama de financistas aúna lo público y lo privado, hace dialogar el cine y la televisión, pone a lo universitario y militar como fuentes de ecuación en servicio de lo audiovisual. Los múltiples formatos de exhibición reconocen múltiples públicos. Al mismo tiempo, la colección marca lo internacional y heterogéneo de los pueblos que se autodefinieron, sugiriendo muy sutilmente un pan americanismo, y ciertamente destacando como tanto en las independencias como hoy, las migraciones y relaciones internacionales -comerciales, diplomáticas, culturales- nos hacen fuertes y es un valor que debemos defender por doscientos años más, como los Libertadores defendieron estas virtudes, incluso sacrificando los ideales propios y el reconocimiento en pos de un bien común mayor.

\section{Notas}

1. La investigación realizada para este capítulo fue posible gracias al programa de Postdoctorados de Fondecyt, Chile, proyecto Folio 3150632.

2. La colección fue presentada el 21 de septiembre de 2009 en el Hotel María Cristina de San Sebastián. Al acto asistieron Ferrada, Camilo Vives, director del Instituto Cubano 
de Arte e Industria Cinematográficos (ICAIC), Ignacio Hernáiz, director del Canal Encuentro en Argentina, así como los productores Sancho Gracia (Lusa Films) y José María Morales (Wanda Films), el realizador argentino Leandro Ipiña, y los actores Rodrigo de la Serna y Rodolfo Sancho, que protagonizan las películas dedicadas al General San Martín y a José Gervasio Artigas, respectivamente (RTVE.es, 2009). TVE compró los derechos de exhibición de las primeras seis obras, aportando de este modo a su creación (Morales, entrevista personal 2017).

3. Agradezco al investigador Ignacio del Valle, quien sugiriera esta veta de análisis.

4. Bolivar el hombre de las dificultades, se produjo en diez meses, pero tuvo un trabajo previo de seis años y un costo total de 17 millones de bolívares (2.7 millones de dólares aproximados al 2013). La obra mexicana contó con un presupuesto de 60 millones de pesos mexicanos (4.5 millones de dólares) y fue distribuida por la major estadounidense 20th Century Fox.

5. Por ejemplo, sobre Martí se había estrenado La rosa blanca (Momentos de la vida de Martí), de Emilio Fernández e Íñigo de Martino (1954) y Páginas del diario de José Martí, de José Massip (1972). Sobre Hidalgo, El grito de dolores o la independencia de México, de Felipe de Jesús Haro (1907) y ¡Viva México! de Miguel Contreras Torres (1934). Sobre Bolívar, Simón Bolivar, de Alessandro Blasetti (1969) y Bolívar soy yo!, de Jorge Alí Triana (2002). Sobre San Martín El santo de la espada, de Leopoldo Torre Nilson (1970) y El general y la fiebre, de Jorge Coscia (1992). Sobre Artigas, José Artigas, protector de los pueblos libres. Documental del italiano Enrico Gras (1950) y El pequeño héroe de Roberto Bayeto (2006) una de las múltiples películas de animación sobre los próceres en América. Sobre O’Higgins, solo había una obra del mismo director de la aquí trabajada, realizada para televisión: O'Higgins, vivir para merecer su nombre, de Ricardo Larraín (2007). Sobre Joaquim, Inconfidência Mineira de Cármen Santos (1948) y Tiradentes, o Mártir da Independência de Geraldo Vietri (1972). Estas no son las únicas, pero sí un universo para ilustrar años, modos y estilo de películas.

6. Tanto la obra mexicana como la chilena también pertenecen a colecciones locales. La mexicana a una trilogía de líderes de la independencia, perteneciente a Serrano y la chilena a una tetralogía inconclusa de Larraín. La obra argentina es sucesora de la serie de especiales documentales dedicados a las batallas del general San Martín dirigidas por Ipiña (Canal Encuentro, 2008).

7. Si bien no es el objetivo de este trabajo, me siento obligada a cautelar que este texto debe ser leído con recelo. Describe al cine silente como primitivo, trabaja principalmente con cine argentino y mexicano por ser las únicas industrias solventes, según él, sin explicar por qué esto es importante en las representaciones del pasado, además de afirmar incorrectamente que las otras naciones no tienen producción significativa de estos temas. 8. No todos estos conceptos existen en mapudungun y fueron desarrollados para la película con la ayuda del profesor Antonio Chiwaykura. Agradecemos a él y Daniel Kiblisky por ayudarnos con la escritura correcta de estas palabras. 


\section{Bibliografía}

Barceló Vázquez, L. [S/F]. “Arquitecto de fantasías”. En Radio Rebelde http://www.cubacine. cult.cu/sitios/ficcion/muescoment.php?CM=050908 [revisado diciembre 2017].

Bossay, C. "El niño rojo (Ricardo Larraín, 2013)", En El Agente cine, octubre 2014. En http:// elagentecine.cl/2014/10/23/el-nino-rojo-ricardo-larrain-2013/

Bowen, A. Entrevista personal. 15 diciembre 2017.

De España, R. (2002) Las sombras del encuentro: España y América, cuatro siglos de historia a través del cine. Diputación de Badajoz.

Gordon, R. (2009). Cannibalizing the Colony: Cinematic Adaptations of Colonial Literature in Mexico and Brazil. Purdue University Press.

Lorite, A. Marzo 2011. "Los héroes libertadores llegan a las pantallas de América Latina" https://elpais.com/cultura/2011/03/10/actualidad/1299711612_850215.html [revisado octubre 2017].

Morales, J. M. Entrevista personal. 01 marzo 2018.

Pagés, A. (2011). “A veces las películas son fascinantes por un hecho azaroso". Analecta Literaria. http://testimoniosautorizados.blogspot.cl/2013/03/leandro-ipina.html [Revisado octubre 2017].

Rosenstone, R. (1995). Visions of The Past: The Challenge of Film to Our Idea of History. Cambridge: Harvard.

RTVE.es, septiembre 2009. “TVE 'baja de la estatua' a los libertadores latinoamericanos en su bicentenario" http://www.rtve.es/noticias/20090921/tve-baja-estatua-libertadoreslatinoamericanos-su-bicentenario/293324.shtml [revisado octubre 2017]

Vertele.es, septiembre 2009. "Rodolfo Sancho será uno de los tres "Libertadores" de TVE” http://vertele.eldiario.es/verteletv/actualidad/Rodolfo-Sancho-LibertadoresTVE_0_1065193490.html [revisado octubre 2017].

Wanda Films. "Libertadores. Una colección de 8 películas sobre los héroes de la independencia de América Latina”. España, 2010.

Zweig, N. (2013). "Los Libertadores as Crossover Cinema". En Crossover Cinema. Crosscultural Film from Production to Recepction. Routledge.

González, R. "Vida de Simón Bolívar inspira la cinta más cara del cine latinoamericano" en La Tercera, 11/09/2013 http://www.latercera.com/noticia/vida-de-simon-bolivar-inspirala-cinta-mas-cara-del-cine-latinoamericano/ [Revisado octubre 2017].

Abstract: The bicentennials of the Latin American Independencies bred a wide range of audiovisual productions created by and for television and cinema, reflecting on the processes of independence as well as on the realities of the colonies. This vast production includes the Libertadores collection, which was designed to be eight historical fiction films that would narrate epic stories of Independence leaders from various Latin American countries: Argentina, Brazil, Chile, Cuba, Mexico, Peru, Uruguay and Venezuela. On its first stage, the collection was co-produced by the Spanish production company Wanda Films, together with Lusa Films, and TVE (the Spanish public radio and television 
company), alongside local film and television production companies from Latin America, both private and state-owned. The project faced difficulties along the way and weathered a hiatus in the middle of the production process. It was then partly resumed, premiering a film as late as 2017, and canceling the last film. The Libertadores collection can be characterized as 'Crossover Cinema': national and international, from different media and with different production processes and visual reflections, while responding to the widespread idiosyncrasies of these countries. By analyzing seven films, this chapter assesses which elements of the Latin American republics' foundational pasts were chosen to be highlighted during the bicentennial celebrations, and how these decisions speak of the present of the production periods. To do so, the chapter takes into account a detailed array of production modes and phases in Latin America; the representation of the dynamics between the Spanish Empire and the revolutionary and victorious Latin Americanists; the manifestations of self-determination that emerge from the films, and finally, individual aspects of the liberators'characters and lives. In this way, this study seeks to identify how these proindependence historiophoties become a proposal of values to understand the identity of these countries, at the point of their bicentennials, within a globalized world.

Keywords: historiophoty - representation - independence - identity - coproduction.

Resumo: Durante os bicentenários das independências em Latino América se gestou uma ampla produção audiovisual criada por e para a televisão e o cinema, que refletia sobre as independências e as colônias. Entre esta vasta produção se destaca a coleção Libertadores, desenhada para estar composta por oito cintas de ficção histórica que narrariam histórias épicas de líderes independentistas de diferentes países latino americanos: Argentina, Brasil, Chile, Cuba, México, Peru, Uruguai e Venezuela. Na primeira etapa, esta coleção foi coproduzida pela produtora espanhola Wanda Films, junto com Lusa Films e a empresa de rádio e televisão pública espanhola TVE, junto com produtoras de cinema e televisão locais de Latino América, tanto privadas como públicas. O projeto enfrentou dificuldades para sua concreção e sofreu um hiato na metade do processo de produção. Foi retomada em parte, estreando uma obra recém em 2017, e cancelando a última das obras. A coleção Libertadores se caracteriza como "cinema de cruzamentos": nacionais e internacionais, de diferentes meios e com diferentes modos de criação e reflexão visual, respondendo a todas estas diferentes idiossincrasias. A partir da análise de sete obras, este trabalho avalia que elementos dos passados fundacionais das repúblicas latino-americanas se decidiram destacar durante as celebrações dos bicentenários das independências, refletindo sobre o presente dos períodos de produção. Destacam-se particularmente a radiografia de modos e estados de produção das obras em Latino América; a representação das dinâmicas entre o império espanhol e os revolucionários e vitoriosos latino- americanistas; as manifestações de autodeterminação que aparecem nas obras, e, finalmente, os aspectos das individualidades dos libertadores. Este estudo procura identificar como estas historofotias independentistas convertem-se numa proposta válida para entender a identidade dos povos do bicentenário no mundo globalizado.

Palavras chave: historiofotia - representação - independência - identidade - coprodução. 